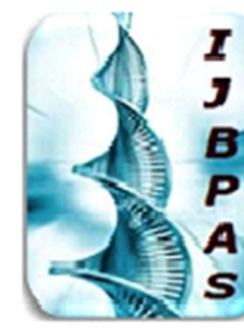

International Journal of Biology, Pharmacy and Allied Sciences (IJBPAS)

'A Bridge Betueen Caboratory and QRendo'

www.ibpas.com

\title{
EFFECT OF YOGA EXERCISE WITH HEALTHY DIET ON SELECTED PHYSIOLOGICAL VARIABLE AMONG THE UNDERGRADUATE WOMEN STUDENT
}

\author{
SUMITRA DAS ${ }^{1^{*}}$ AND DR. P. YOGA ${ }^{2}$ \\ 1: Research scholar, Alagappa University College of physical education, Alagappa \\ University, Karikuddi, Tamilnadu, India \\ 2: Assistant professor, Alagappa University College of Physical Education, Alagappa \\ University, Karaikuddi, India \\ *Corresponding Author: Sumitra Das; E Mail: dassumi033@gmail.com
}

Received $24^{\text {th }}$ July 2021; Revised $26^{\text {th }}$ Aug. 2021; Accepted $30^{\text {th }}$ Sept. 2021; Available online $1^{\text {st }}$ Nov. 2021

https://doi.org/10.31032/IJBPAS/2021/10.11.1107

\begin{abstract}
Many Research shown that for student proper nutrition is important, when student had proper nutrition it will help to learn better, focus on class and able to understand more. Yoga helps to maintain physical health and mental health and yoga gives good vibes to do something that more important every individual. The main objective of the study was to find out effect of yoga exercise with healthy diet on selected physiological variable among the undergraduate women. For my study I choose 30 women student as a subject from Alagappa University, karaikuddi, Tamil Nadu and their age range 18 to 25 years. Selected subjects were divided into two group $(15 \times 15)$, Control group do not take part any type of training they follow their regular activity. Selected physiological variable, Systolic blood pressure was taken as criterion variable in this study. The pre-test were organized on two subjects groups of the study which measure systolic blood pressure through sphygmomanometer and pre-test conduct before given them training. Experimental group actively participate to yoga exercise and follow proper diet. Researcher prepare training schedule for 6 week, weekly four days every morning 40 minutes and collect current data after the post- test without delay. For Statistical techniques ' $t$ ' ratio was used to analyses the mean of the pre-test and post test data
\end{abstract}


experimental group and control group. The significant difference between yoga exercise with healthy diet recommended given to the experimental group on systolic blood pressure when compared to control group.

\section{Keywords: Healthy Diet, Systolic Blood Pressure, 't' ratio, Yoga}

\section{INTRODUCTION}

Regular yoga practice is good for health, it will help to creates awareness, mental clearly and calmness, improve body function ability, relief cornice back pain, illness. Relax body mind, help to maintain body posture, through yoga control mind "doctor says". Yoga is a great way to connect mid to body and sound to mind. Astanga yoga practice promote health benefit through asana, pranayama, Dayana, Samadhi etc. every day yoga practice reduce diseases [1]. Yoga is all about to connect body, mind and spiritual. There are six way to connect, karma yoga, jnana yoga, raja yoga, bhakti yoga, hatha yoga, trantra yoga. Each yoga posture contributes different aim and objective in human life. Yoga is balanced body mind, through yoga direct connect to emotions, state balanced of behavior [2]. Yoga works as a multi complementary health related fitness and arts for promoting health related benefits for sports persons. Nowdays every trainer or coach suggests yoga practice regularly for better promote motor components. Yoga has been used since ancient times that involve pranayama, meditation, asanas etc. [3]. People say that yoga helps to find the solution when they suffering from health issues and yoga help to all-round development of cool, stress free, and physically fit body [4]. The objective of yoga is solidarity of the body, brain and soul with the attention on body stance, breathing and contemplation. A few types of yoga exist to address the issues of differing ways of life and characters [5]. Yoga provides a platform to perform various workouts in any time or any place. It is being provided that yoga uses to regulate the entire body from top to bottom [6]. Yoga is a great soul of the Universe. It can promote the social well-being through limps of yoga (Asanas, Pranayama, Kriyas, Mudras and Meditations) [7].

Diet is a basic thing which we ignore and there are so many of students they do not focus on their diet Because of study. There are so many students those love to do more study but they are not satisfied the result. So that's why they are not flow their diet plan, as a result either they get obese or skinny and during adolescent age student face many changes related to the physical health, mental health, social life style even their behavior and related to academic. It is 
a very important to know every student what they should eat and why. Every student wants to shine, and their spark is connected to their efforts and their healthy diet. Student are able to learn better when they are well nourished, and eating healthy meals has been linked to better memory and concentration, and alertness during the whole day. If anyone skips their breakfast it will directly affect on BMI (body mass index). Science says that proper carbohydrate, protein, and vitamin D must.

\section{RESEARCH METHODOLOGY}

\section{Research Subjects Selection}

The main objective of the study was to find out the yoga exercise combined with a healthy diet recommended on systolic blood pressure among undergraduate college women. This goal of the study thirty college women were selected randomly as a problem of the study. Subjects and age ranged between 18-25 years for research purposes.

\section{Selection of Variable}

Independent Variable

- Yoga Exercise with Healthy Diet Recommended

Dependent Variable

- Systolic Blood Pressure

EXPERIMENT GROUP DESIGN AND IMPLEMENTATION

The selected students were separated into similar two groups of fifteen subjects for each group, such as yoga exercise with a healthy diet recommended experiment Group and control group. The experiment group underwent yoga exercise with healthy diet weekly 4 , days for 40 minutes for 6 weeks. Control group, they did not take part in any kind of exercise, they just doing their regular activity. And Physiological selected variable name systolic blood pressure was chosen as measure of variable. Selected yoga exercise with healthy diet recommended group take part in yoga exercise for 6 weeks and before start training pretest conduct and collect data after that selected experiment group were tested systolic blood pressure through the sphygmomanometer and after completing 6 week exercise schedule without delay researcher collect the data immediately.

\section{Statistical technique}

For this study ' $t$ ' test was used to solve and measure the difference between the two groups in some respects.

\section{Level of significant}

The 0.05 level of confidence was stable to test the level of significance which was calculated as correct.

\section{STATISTICAL ANALYSIS}

Difference between the two research groups among the mean of the experimental group and there would be any significantly different ways find out by pre-test and after 
post-test. The collect data were analysed and dependent ' $t$ ' test was used to measure with 0.05 levels as dependence.

The Table 1 shows that the mean values of pre-test and post-test of the control group on systolic blood pressure were 123.46 and 123.60 respectively. The obtained ' $t$ ' ratio was 0.52 , since the obtained ' $\mathrm{t}$ ' ratio was less than the required table value of 2.14 for the significance at 0.05 level with 14 degrees of freedom it was found to be statistically insignificant. The mean values of pre-test and post-test of the experimental group on systolic blood pressure were 123.66 and 124.53 respectively. The obtained ' $t$ ' ratio was $4.51 *$ Since the obtained ' $t$ ' ratio was greater than the required table value of 2.14 for significance at 0.05 level with 14 degrees of freedom it was found to be statistically significant. The consequence of the study showed that there was a significant difference between control group and experimental group in systolic blood pressure. It might very well be finished up from the result of the study that's experimental group worked on systolic blood pressure due to six weeks of yoga exercise.

Table 1: Analysis of t-ratio for the pre and posttests of experimental and control group on Systolic blood pressure (Score in $\mathbf{~ m g / d l ) ~}$

\begin{tabular}{|c|c|c|c|c|c|c|c|c|c|}
\hline \multirow{2}{*}{ Variables } & \multirow{2}{*}{ Group } & \multicolumn{2}{|c|}{ Mean } & \multicolumn{2}{|c|}{ SD } & \multicolumn{2}{|c|}{ SE } & \multirow{2}{*}{ 't' } \\
\cline { 2 - 8 } & & Pre & Post & Pre & Post & pre & Post & & ratio \\
\hline \multirow{2}{*}{$\begin{array}{c}\text { Systolic blood } \\
\text { pressure }\end{array}$} & Control & 123.46 & $\mathbf{1 2 3 . 6 0}$ & $\mathbf{0 . 8 3}$ & $\mathbf{1 . 1 8}$ & $\mathbf{0 . 2 1}$ & $\mathbf{0 . 3 0}$ & \multirow{2}{*}{$\mathbf{0 . 5 2}$} \\
\cline { 2 - 9 } & Experimental & $\mathbf{1 2 3 . 6 6}$ & $\mathbf{1 2 4 . 5 3}$ & $\mathbf{0 . 8 9}$ & $\mathbf{1 . 1 8}$ & $\mathbf{0 . 2 3}$ & $\mathbf{0 . 3 0}$ & & $\mathbf{4 . 5 1}$ \\
\hline
\end{tabular}

$*$ Significance at .05 level of confidence for the degree of freedom $14=2.14$

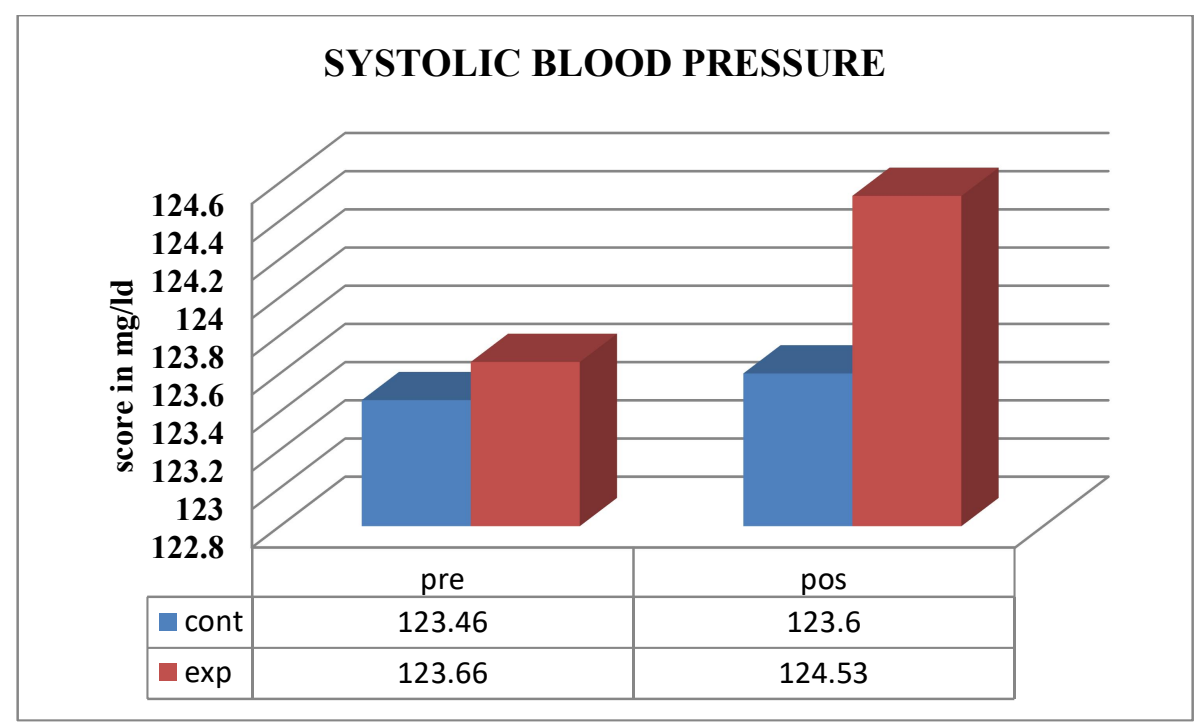

Figure 1: Bar Diagram Showing the Pre and Post Mean Values of Experimental and Control Group on systolic blood pressure

(Score in $\mathbf{m g} / \mathbf{d l})$ 


\section{DISCUSSIONS ON FINDINGS}

The final result of the study indicates that the experimental group, namely yoga exercise with a healthy diet group, had significantly improved the selected dependent variable, namely systolic blood pressure, when compared to the control group. It is also found that the improvement is caused by systolic blood pressure when compared to the control group.

\section{CONCLUSION}

On the basis of the research results obtained the following conclusions are drawn,

1. There was a significant difference between experimental and control group on systolic blood pressure after the training period.

2. There was a significant improvement in systolic blood pressure. However the improvement was in favour of the experimental group due to 6 weeks of yoga exercise with a healthy diet recommended.

\section{ACKNOWLEDGEMENT}

The author thanks all the participants who had volunteered throughout the study.

CONFLICT OF INTEREST

Nil

SOURCE OF FUNDING

Self

\section{REFERENCES}

[1] Alaguraja, K, \& Yoga, P., Analyze of combined asanas pranayama practices on psychosocial parameters among sports people. Indian Journal of Applied Research, 9(10), (2019), pp. 73-74.

[2] (bhagavad gita- lord Krishna defines).

[3] Rai, Marina., Yoga, P., Alaguraja, K., Selvakumar, K., \& Sumitra Das., The power of yoga. International journal of advanced science and technology, 29(03), (2020), pp.6225-6229.

[4] Das Sumitra., Yoga, P., Alaguraja, K., Selvakumar, K., Rai, Marina., Consequence of Yoga and Rowing. International Journal of Advanced Science and Technology, 29(03), (2020), pp. 7079 - 7084.

[5] Das, Sumitra. \& Yoga, P., Effect of Yogic Package on Body Mass Index among Rural School Girls. Journal of Information and Computational Science, 9(10), (2019), PP 462-467.

[6] Selvakumar, K., Parthasarathy, S., Rai, Marina., Das, Sumitra., Impact of yin yoga on body mass index among obese patients, International Journal of Sports, Health and Physical Education, 1(01), (2019), pp.17-20. 
[7] Selvakumar, K., Parthasarathy, S.,

Rai, Marina., Das, Sumitra., Spiritual meditation on selfconfidence, International Journal of Sports, Health and Physical Education, 01(01), (2019), pp. 2124.

[8] K, Selvakumar., S, Parthasarathy., Rai, Marina., Das, Sumitra., The sun salutation practices on body mass index among rural school boys. International Journal of Sports, Health and Physical Education. 01(02), (2019), pp. 0104. 